\title{
Chapter 11 \\ The Difficulty of Integrating Religious Diversity into Intercultural Approaches to Education
}

\section{Introduction}

It is difficult to consider religious diversity within the general framework of intercultural approaches in education. On the one hand, the school cannot ignore the permeability of the school precincts to the pupils' religious beliefs. On the other, religion, as one of the dimensions of culture, can tend to adopt a hegemonic attitude not very reassuring for cultural relativism. In fact, taking religion seriously within the school means not underestimating its private and personal nature, which is likely to conflict with the public character of the educational institution.

Following the numerous terrorist attacks that have taken place in the world, especially those of 11 September 2001, international and intergovernmental organizations, such as UNESCO and the Council of Europe, have issued various recommendations stressing the importance of understanding religion as an integral part of multiculturalism. In these documents, education is considered as the key to reaching better knowledge and understanding of different visions of the world and religions in order to promote peace in a plural society (United Nations, 2004; Council of Europe and Keast, 2007).

The objective of this chapter is to explore the ways in which schools in different contexts take religious and spiritual diversity into consideration. In the first place, we are interested in the challenges posed by this theme within the school. Next, we pay attention to four key concepts, namely: spirituality, secularism, education about religious traditions and interreligious dialogue. Thirdly, we present different ways that countries have dealt with religion within the school. Finally, we offer an analysis of some critical incidents connected with the pupils' religious affiliations. 


\section{Why is Taking Religious Diversity into Account Difficult for the School?}

When the subject of religion within the school is mentioned, everybody knows that it may lead to a great deal of squabbling and arguments. We should anticipate these emotional outbursts, but above all understand the reasons for them in order to better comprehend religious attitudes within education. For these reasons, we have identified six possible sources of problems about how the school confronts religious diversity.

Firstly, even if certain principles to be mentioned later in this chapter seem to correspond to the existing situation in several education systems, it still seems important to pay attention to each particular context when dealing with religion in the school. In fact, important differences could exist between two education systems. For example, to understand the relationship between the French education system and religion, one must go back to the end of the nineteenth and beginning of the twentieth centuries, for it was at this time that the French school declared itself as "The School of the Republic", rather than a religious school. The 1905 Law marks a turning point for the school. This moment is founded on three principles: the State is neutral as far as religion is concerned; freedom of conscience for all; and neutrality in the service of pluralism (Chauvigné, 2017). Thus, the school separated itself from the clergy, but also from any form of spiritual involvement. This lay rupture marked a first separation between the public school and private life, supposed to be governed by laicity (Balibar, 1991). A first tension arises here for: "The school is politically sensitive because it is the place par excellence for this connection, since in itself it is neither purely 'public' nor purely 'private', yet without any contact between these two fictionally disjointed spheres" (Balibar, 1991, p. 76). In other words, the separation of the State and religion made the school a meeting point between the private individual and the public and neutral character of the institution.

In other education systems, history has also had an impact on the place granted to religion in the school: Quebec, for example, has only recently separated itself from religious governance of the school (until the 1960s, school commissions ${ }^{1}$ were either Catholic or Protestant and were responsible for organizing and managing the education system); the United States, Spain and even Italy have education systems in which religion forms a regular part of the public school.

Evidently, these different conceptions of the place and legitimacy of religion in the school raise questions, since today this institution is confronted with a vast range of religions (Willaime, 1995).

The second potential source of tension is found precisely in the individual, communitarian, varied - in a word, heteroclite — character of religious practice. While there are religious faiths consisting of institutions, the way in which a person chooses to live his or her faith remains personal. Therefore, despite the ceremonies and rites attended by large numbers of people, varied practices may nevertheless arise

\footnotetext{
${ }^{1}$ Regional institutions for the management of education systems in Canada.
} 
within particular religious communities. Lamine (2018) has drawn attention to a trend among researchers who consider that all practising religious believers are "100\%" so, without any possible variation. His analysis draws attention to the possible uniqueness of an individual's faith, but also to the fact that numerous matters may influence religious experience. Thus, it is possible to have two Catholic believers who do not experience their religion in the same way, yet they belong to the same "classification" as members of a given religious group. The school itself must then take note of this inconsistency and should not consider groups and practices to be invariable. In fact, religion, like culture, is a dynamic process and is open to different interpretations.

The third source of tension presented here could be entitled "religious ethnocentrism". Indeed, Lamine (2018) draws attention to a Western conception of spirituality:

The definition of religion as it has emerged in the Western world, influenced by the Age of Enlightenment and by Protestant reforms, is intolerant of intense bodily practices (fasting, daily prayers) and visible signs of faith (religious insignia, assertions) as has been demonstrated at length by Talal Asad in his historical anthropology of secularization (Asad, 2003; Lamine, 2018, p. 4).

Thus, it is possible that numerous individuals or institutions view participation in religion through this cultural filter and are therefore tempted to express a negative opinion about non-conformist practices. There would therefore be a "good religion" (Lamine, 2018, p. 5), or at least a good practice of the religion and its rites. This arbitrary and ethnocentric differentiation is likely to banish rites that are considered unorthodox. In contrast to this form of ethnocentrism, it will still be necessary to develop the religious relativism required for living together.

The fourth source of tension that we have identified is the fear that can be provoked by the presence of religion in the school. The fear of dogmatism, fanaticism and extremism arising from a tense international situation, cannot however be a reason for excluding the Other considered to be different or rather too closely associated with the origins of our fears. There are other fears about religion. For example, the confrontation between science and belief might give the impression of a desire for one of them to dominate the other. According to Lamine (2018), this opposition is not, however, realistic since, in fact: "one of them deals with cognitive rationality while the other relies on the symbolic" (Lamine, 2018).

Next, the fifth tension is speculative. Indeed, it seems that today the resolve to pay attention to religion/spirituality in the school is faced with the decline in religious practice or of belonging to a particular religion. There is, however, still a need to take religious diversity into consideration in the school even in situations where the majority of the population does not practice any kind of religion.

Finally, the sixth tension targets not the school but religions. On the one hand, one could assume that the dogmatic vision of truth prevents any form of interaction between religions; this first assumption could be a major stumbling block in the development of intercultural approaches in the realm of religion. On the other hand, if intercultural approaches came to the fore in the 1950s and 1960s, it is because they represented a useful tool when demanding rights (on gender equality, on the ending 
of discrimination based on ethnicity, on sexual orientation, on the right to voluntary abortion). However, to varying degrees, religions did not actually support the majority of these social revolutions. On this subject, it is normal in an intercultural perspective to retain a certain scepticism about the entry of religions into the school. Nevertheless, as has already been mentioned, religious practice is diverse, so "religion" cannot be entirely limited to the attitudes adopted by institutions representing religions.

In this case, "tension" should not be simply understood in a negative sense. It represents above all the issues raised when considering religious diversity in the school. To understand the different ways they overlap, one must grasp this theme as a whole by looking at different aspects, such as: the difficulty of religious neutrality ${ }^{2}$ within the school; the universalism or the dogmatism of monotheistic religions; the diversity of spiritual practices; the wariness associated with certain religious affiliations ${ }^{3}$; and the fear of separatism and communitarianism. To deal with religion within the school or at least to raise questions about it requires adopting an attitude of openness, tolerance and relativism to what, for some people, seems incomprehensible. However, it is important to be aware of the risks of absolute cultural extremism, which would mean accepting everything in the name, for instance, of religious tolerance.

\section{Key Concepts: Spirituality, Laicity, Religious Traditions and Inter-Religious Dialogue}

An analysis of concepts such as spirituality, laicity, education about religious traditions and interreligious dialogue seems necessary for an understanding of the place of religion within the school.

Very often, the terms "religion" and "spirituality" are used as interchangeable synonyms. However, it seems to us important not to confuse them. Indeed, when one speaks of "religiosity", one immediately thinks of the institutional or, more particularly, the monotheist religions (Judaism, Christianity and Islam). Spirituality has two functions: it directs our regard to the world and it determines people's ultimate goal. Animist and "free thinking" societies have a spirituality that must be recognized in the same way as that of the institutionalized religions. In other words, when time is devoted to religious beliefs and religious faith in the school, it is reasonable to devote some of it to non-religious beliefs and to different forms of spirituality.

Laicity is a concept that may take different forms according to the epoch, the context and the definition attributed to it. In fact, even if the word has remained the same over time, its actual meaning can "be interpreted differently according to the social context and the philosophical and political position" (Lavoie, 2018,

\footnotetext{
${ }^{2}$ The pupils do not leave their religion at the school gate.

${ }^{3}$ At the time of writing, some religious affiliations arouse more fear than others: in this respect, Islam is the most censured. The tense international climate and the demands by certain extremist groups contribute to augmenting and fortifying these fears. Unfortunately, these attitudes sometimes become sweeping generalizations employed to discriminate against all Muslims.
} 
p. 30). Therefore, the first aspect to be recalled concerning this concept is that it incorporates a flexible definition depending on the context, but also in the way that those involved interpret it. In this book, we have decided to present a definition of laicity essentially based on the French context, a place where the debate is often very fierce. Not widespread, this definition does however allow the reader to identify the issues and tensions associated with the implementation of such a concept.

One can place the origins of laicity at the moment when France adopted the Law of 1905 laying down the terms for the separation of the Church and the State. At this time, the principles respected were freedom of conscience, the religious neutrality of the State and neutrality in the service of pluralism (Chauvigné, 2017). This means that laicity allowed each individual to choose freely their affiliation. This form of laicity is also called the laicity of neutrality or of separation (Chauvigné, 2017).

Between 1989 and 2003, laicity became a "laicity of conciliation" (Chauvigné, 2017). In fact, following the affaire des foulards (the headscarf affair), ${ }^{4}$ the French State maintained the "spirit of 1905" and therefore the idea of liberal laicity: the "users" had the right to wear a sign reflecting a religious affiliation in public outside the school (Chauvigné, 2017).

In 2004, there was a similar debate, but the tone of the discourse had changed and so, once again, had the meaning of laicity. Chauvigné (2017) called it "the laicity of neutralization or of unification". Religious symbols said to be ostentatious were banned (in the name of State neutrality and therefore of the school). This renewed laicity then found itself isolated between the respect of religious faith and complete ignorance of it (Chauvigné, 2017).

Finally, between 2000 and 2016, this author mentions a laicity for living together. The State imposes its Republican universalism, which throws doubt on its supposed neutrality (Chauvigné, 2017). Indeed, in the name of this universalism, individuals' particularities (in this case religious ones) are consigned to a simple private space. Furthermore, a norm established by the State is not automatically neutral, since it may reflect some cultural characteristics more than others and therefore establish different thresholds of tolerance. Equality in the name of universalism could therefore be a source of inequality between individuals and cultural or religious practices. Gaudin et al. (2014) speak of an intelligent laicity to emphasize a certain flexibility.

The evolution of the concept of laicity in France draws attention to its plasticity and its numerous interpretations. It is then valid to ask: what is laicity? On several occasions in the literature, we find two main meanings, which may also reflect what has taken place in France (Table 1).

To sum up, liberal laicity leaves a wide prospect for individuality and is based on its acceptance within a society united by its diversity. As for laicity considered as "universal", it is based on an egalitarian ideal in which private and public are completely separate and religion is reserved for personal practice.

In discussions concerning the place of religion in the school, one often finds the concept of education about religious traditions (fait religieux) (Gaudin et al., 2014).

\footnotetext{
${ }^{4}$ The headscarf affair took place in 1989; it was the first time that the matter of the right to wear a veil within the school appeared in a public debate.
} 
Table 1 Two models of laicity

\begin{tabular}{l|l|l}
\hline Type of laicity & Universal or Republican laicity & Liberal or inclusive laicity \\
\hline Characteristics & $\begin{array}{l}\text { Stresses the separation of the public } \\
\text { and the private (Portier, 2017) } \\
\text { General interest before individual } \\
\text { interest (Chauvigné, 2017) } \\
\text { "Sacralization of social morals" } \\
\text { (Balibar, 1991, p, 77) } \\
\text { Not against religion, but advancement } \\
\text { of a "religion of science" (Balibar, } \\
\text { 1991, p. 77) }\end{array}$ & $\begin{array}{l}\text { 2017) } \\
\text { Insists on freedom of (individual) } \\
\text { conscience (Portier, 2017) } \\
\text { Encourages dialogue (Balibar, 1991) } \\
\text { Mutual recognition of opinions, beliefs } \\
\text { and ways of life (Balibar, 1991) } \\
\text { "Assumes the demonstration of } \\
\text { knowledge (Balibar, 1991) }\end{array}$ \\
\hline Issues & $\begin{array}{l}\text { Risks to blend religious differences } \\
\text { Promotion of an equality which does } \\
\text { not allow the particular needs of some } \\
\text { cultural/religious groups to be } \\
\text { considered } \\
\text { Places doubt on the State's neutrality } \\
\text { (Chauvigné, 2017) }\end{array}$ & $\begin{array}{l}\text { The fear of communitarianism that this } \\
\text { approach may instigate }\end{array}$ \\
\hline
\end{tabular}

Its definition allows the fantasies and the imaginary surrounding the field of the sacred to be clarified when it enters into the school. In fact, particularly in France, "education about religious traditions" is the only way that the spiritual dimensions may be incorporated into teaching.

In countries like France, where a strict definition of laicity applies, religions do not have a place, or only a very small one, in the school. The inclusion of education about religious traditions does allow their histories to be taught. It is, furthermore, the extension of teaching religious traditions in the same way as other disciplines (for example: the history of art, French, literature, philosophy, etc.) which has resulted in the use of the term "education about religious traditions" (Carpentier, 2004). But then, if we intend to examine closely the work of Chrétien de Troyes, or if we analyse "Pascal's wager" (le pari de Pascal), or again if we study the rites of ancient Egypt, what exactly are we going to teach?

In order not to end up teaching religion, it is necessary to define "traditions". Several signposts reveal its structure: in this case "traditions" does not designate any particular religion; it is observable and evolving (Debray, 2002). To sum up, the introduction of the concept of "education about religious traditions" leaves a place for religion in the school, as long as it is dealt with in a neutral way and particularly if it describes how religion has had an impact on human beings and their civilizations. Education about religious traditions is, in this case, quite separate from religion: it deals with its social aspects but not its spiritual or theological content.

Increasingly, questions concerning religion lead to the idea of interreligious dialogue. Promoted by organizations such as the Council of Europe or UNESCO, it is interesting to understand what lies behind this approach to religions and to understand its roots as far as intercultural approaches in education are concerned. 
Religiousness, either in order to understand its place within the public arena or its "actual" objectives, is frequently studied from a teaching point of view. Interreligious dialogue allows a first appreciation of these academic studies of religion; without actually refuting them, it seeks to compare them. It is, in fact, with the intention of understanding the subjectivity of the practices and interpretations of faith that religious people are invited to describe them (Basset, 1990).

\footnotetext{
The specificity of the dialogue approach depends basically on the fact that it leaves to the faithful the possibility and the task of defining themselves and expressing the meaning of their faith in their comprehension of existence and their commitment to the world. Clearly, we have here a profound methodological mutation to the extent that attention is not paid exclusively to the objective data represented by the texts, the beliefs or the rites of a particular religious tradition, but just as much to what such a text, such a dogma or such a practice mean for the believers (Basset, 1990, p. 30).
}

Thus, just as in Chap. 4, we promote a dynamic approach to culture leaving room for individuals' subjectification of liberty; interreligious dialogue pays attention to its interpretation, and that with a comprehensive goal (Basset, 1990). Basset (1990), while developing key concepts for an understanding of interreligious dialogue, highlights some characteristics of this concept: (1) it involves a personal viewpoint that comes from first-hand experience; (2) it requires that the participants in the discussion have a common point of view: humanity or the belief in the existence of a superior being; (3) it assumes a belief in the faith; (4) it considers difference as a positive resource for each person involved in the dialogue; and (5) the interreligious dialogue is personal and should allow questions concerning the meaning of existence to be dealt with (Basset, 1990).

Interreligious dialogue seems to us to be an interesting tool in an educational context; however, it is necessary to reflect upon the five characteristics proposed by Basset (1990). It is possible to imagine exchanges between pupils on the subject without any of them actually possessing any religious affiliation. Spirituality can be dealt with in a critical manner-open, appreciating difference. It can also deal with different themes, such as inter-individual relationships, respect, tolerance, benevolence; in short, intercultural competences useful for living in a diverse world.

\section{Different Contexts, Different Approaches to Religious Diversity}

Addressing religious diversity is not the same everywhere in the world. It depends upon the choice of national policies, the international situation, the history of each nation and, as we will see below, the present conception of cultural and religious plurality. To understand the differences that may exist between States, we will present three situations (France, Quebec and the Canton of Geneva) where religion in the school has been dealt with in different ways. By taking inspiration from various 
research and professional works on this subject, we will attempt to reply to two questions: what is the place of religious diversity and what form does it take in the school?

In France, the approach to religious diversity is mainly constrained by the Republican conception of laicity. As we have seen earlier in this chapter, this conception implies a universalism towards which each person should (and would) attempt to reach. The initial idea being that since the school trains all citizens to be members of the same nation, the religious aspect is reduced to the strict minimum so as not to antagonize any particular group. Nevertheless, the French model of considering religion should not be reduced to universalism. It is complex and other aspects remain to be analysed.

Firstly, concerning a universalist vision almost oblivious to diversity (Chauvigné, 2017), there is a wish to liberate young people from potential family influence (Estivalèzes, 2009). It is as if the universalist lay framework should allow other possibilities to be explored and, in this way, by erasing differences, to make it open to all interpretations. Nevertheless, the denial of religious otherness can, for some people, have something in common with ignorance about one's faith and can then be interpreted as the rejection of an aspect making up one's cultural identity.

Secondly, the French model is not, despite its sacred Republicanism, opposed to dealing with certain particular demands (for example, through providing an alternative menu for pupils with dietary restrictions connected with their religion) (Estivalèzes, 2009).

Thirdly, from the point of view of school curricula in France, it seems that religion has its own unique place. According to Estivalèzes (2009), the study of education about religious traditions is not included in the curriculum for civic education. Nevertheless, it is clearly through this discipline that the pupils are introduced to the principle of laicity (Estivalèzes, 2009).

One of the pivots of this model, laicity, should be understood as transcending all religious affiliations, which requires beliefs and practices to be relegated to the private sphere. It is an expression of the wish to make the public domain neutral, at the religious level, to all citizens, whatever their convictions (Estivalèzes, 2009, p. 48).

Thus, the teaching of laicity provides an opportunity to demonstrate that national identity is more important than individual identities. In France, the concept of education about religious traditions, defined above, is often the way religion enters the school, because it allows the historical and cultural aspects to eclipse the spiritual aspects (Estivalèzes, 2009).

The French model is therefore complicated because of its wish to consider religion, while only devoting a place for it that precludes it from competing with national citizenship. There is therefore no competition between the State and religion; thus, the French model of laicity implies a form of ranking which places being part of the nation above any religious affiliation in the school.

The second model that we will present of religion being considered within the school is that of Quebec. A few comments on the context are necessary prior to its analysis. Firstly, it should be made clear that the present identity of the province 
was created on the basis of a strong diversity (this includes First Nations peoples and migrations). Next, note should be taken of recent history, particularly the Quiet Revolution of the 1960s. This event allowed society to free itself from the dominant religion (Catholicism), which today plays a much more marginal role and is no longer "a common and obligatory reference" (Cornellier, 2012, p. 132). Our analysis of the Quebec model takes place therefore in a society that has recently rejected religion and is particularly varied from a cultural point of view.

Nowadays, the place of religion within the school forms part of the teaching of ethics and religious culture (ERC). These courses, introduced in the curriculum in 2008, represent the high point of the deconfessionalization of education because they require a total neutrality on the part of the teaching staff with regard to religious questions (Duclos and Poellhuber, 2017).

The principal objective of this teaching does not aim at religion as such but at living together. The idea is to make ERC a tool for strengthening democracy by making it more open and more tolerant (Leroux, 2007, quoted by Duclos and Poellhuber, 2017). On this subject, the Ministry of Education considered ERC as a true addedvalue in respecting diversity (Duclos and Poellhuber, 2017). In this way, educating pupils about religion is one way of training them for active citizenship in a plural society:

Through proficiency in ethics and in dialogue, the Ethics and Religious Culture Programme has become above all education for living together understood as an education for active citizenship as Martineau and Laville (1998), for example, intended; in other words, "that of a free and critical being, ready for reflective social participation" (p. 62) (Bouchard, Daniel, and Desruisseaux, 2017, p. 78).

Two guidelines give structure to this ethical and cultural religious teaching: they are the common good and the recognition of the other (Cornellier, 2012). However, Bouchard et al. (2017) draw attention to the domination of the "common good" orientation over that of recognizing others. These two axes are carried out through three key competences:

1. To adopt a reflective attitude towards ethical questions;

2. To express an enlightened understanding of religious phenomena;

3. To carry out dialogue with a view to living together (Estivalèzes, 2009, p. 52).

The criticism of Bouchard et al. (2017) focuses on the connection with the competences inculcated, because they reproach this programme for its overly phenomenological approach and its lack of distance from the religious models presented. They even mention a risk of absolute relativism (Bouchard et al., 2017).

Through this second approach, one observes that the application of the principle of laicity may be totally different from one context to another. In Quebec, it is through the idea of citizenship that religious otherness is recognized, while in France, on the contrary, it is the notion of citizenship that allows "national" individuals to be separated from their "private" religious particularities. 
Geneva, as the most culturally diverse canton in Switzerland, is faced with a multitude of religious plurality ${ }^{5}$ (even if those inhabitants without any religion are in the majority). It should be noted that it is the only canton in the country that has included laicity in its constitution (a law voted in 1907) (Cuénod, 2018). As was explained at the beginning of this section, we decided to ask ourselves how religious diversity is considered and what form it adopts within the school. We will attempt to reply to these questions using four approaches: teaching; the school and laicity; the pupils; and school disciplines.

In the Canton of Geneva, teachers are subject to a ruling of neutrality. As representatives of the State and of a lay institution, they may not display any confessional affiliation within the school (DIP, 2016) and cannot therefore wear evident religious insignia in the classroom (DIP, 2016). However, the Department of Public Instruction declares that the neutrality of "State agents" should not prevent them from dealing with controversial, sensitive subjects - in other words, those that trouble:

To affirm that the school is lay is not to renounce dealing with certain subjects which may cause anger, for this would be to forget the school's mission - which is particularly to make the pupil aware of the respect for others and the tolerance that our society sorely needs. A laicity of ignorance, a laicity that is afraid of contact and which refuses discussion, only encourages obscurantism. This is not the laicity that we want (DIP, 2016).

Laicity à la genevoise is not therefore a laicity excluding or neutralizing religion. It would seem rather to aim at its inclusion so as to encourage the learning of apprehension and coming into contact with sensitive matters at the school. Laicity, as it features in the texts of the Geneva Department of Public Instruction, is not the ultimate goal but rather a means of introducing into the school a discussion of sensitive issues. The school gives itself the objective of taking difference (in this case religious) into account in order to avoid a breakdown between families and the institution (DIP, 2016): laicity is a tool, a guide, but does not set boundaries. Furthermore, the State of Geneva completely rejects an assimilationist approach to laicity: it must be a way of encouraging interaction but "it does not intend at all to erase ethnic, linguistic, cultural or religious characteristics for the benefit of a total adherence to the codes of the majority" (DIP, 2016, p. 6).

The application of the principle of laicity in Geneva varies according to the target public. If the teachers must remain strictly neutral, the pupils do not have to follow this same rule. The regulations concerning them foresee that they may wear insignia of religious affiliation, as long as they do not disturb the educational establishment, do not represent a danger for the pupil, allow the satisfactory participation of the pupil and do not assume the attitude of proselytism (DIP, 2016).

In practice, the State of Geneva seems to insist upon offering religion a true place within the school. While this cannot be ignored, it is nevertheless restricted:

\footnotetext{
${ }^{5}$ Roman Catholics: $37.2 \%$; Protestants: $10.2 \%$; other Christian communities (including Orthodox churches and Christian catholic churches): $5.7 \%$; Muslims: $6.1 \%$; Jews: 1\%; without religion: 38.3\%; other religions (Buddhists, Hindus, etc.): 1.6\% (Cuénod, 2018, p. 11).
} 
- No exemption from teaching is tolerated for religious reasons;

- Absences for religious reasons may be tolerated if they are of "short duration" "outside examination periods" and "motivated on serious grounds" (DIP, 2016, p. 11);

- Educational activities (visits to religious establishments, exhibitions, etc.) associated with religion are obligatory as long as they are connected with the objectives of compulsory education (DIP, 2016).

- Celebrations (end of year concerts) are obligatory if they acknowledge the pupils' work, but are optional if their purpose is purely recreational (DIP, 2016).

In Geneva, the teaching of religious education does not have a separate place in the curriculum, as in Quebec. It forms part of the "history" discipline but may also be touched upon during other lessons, for example when examining works of art:

To abstain from showing them (works of art with religious themes) in the name of laicity is equivalent to forbidding oneself from studying the essential elements of humanity's cultural and historic heritage. The school would then have failed to transmit the knowledge necessary to "make the pupils gradually aware of their relationship with the surrounding world, by awakening in them the respect for others, tolerance of difference, the spirit of solidarity and cooperation" as the Law on Public Instruction requires (DIP, 2016, p. 14).

The Canton of Geneva appears to be developing a very consensual policy on laicity in the search for a balance between the neutrality of the State and inclusion or respect for affiliation or personal beliefs. Religious liberty is given minimal restraint and then only when it may harm public health (the obligation to follow educational courses on sexuality) or in the greater interest of the child (religious rules should not interfere with learning).

Despite seeking an apparent consensus and the claim of laicity/neutrality within the school, the religious dimension remains influenced by the respect of local historical festivals. With regard to religion, not all the pupils are equal, since the child who celebrates Christmas benefits from holidays coinciding with this cultural/religious event, whereas those who wish to participate in other religious celebrations (Eid or Hanukkah, for example) have to make a request and await an official permit before absenting themselves. It follows that there is a legitimate historical argument for the ranking of practices and the authorization to practice a religion. This observation arises from our analysis of the Genevan system, although the same situation must exist in numerous other countries where the school holidays are structured around historical religious events.

Our analyses of different education systems and their relationship with religion face a first limit by stopping at this prescribed stage. Indeed, we are basing ourselves here only on texts recommending or authorizing the inclusion of the religious dimension in the school or on research concentrating on this theme. It would be appropriate to take an interest in the teachers' classroom practices in order to know the way they actually function on the subject of their pupils' religious diversity.

Nevertheless, this analysis, even at this prescribed stage, allows the true complexity of the interpretation and the implementation of the concept of laicity 
in the school to be described. Indeed, the three contexts studied claim to be lay, but they all tackle religious questions from different approaches and angles.

\section{The Return of Religions to the School: Between Recognition and Intolerance}

The different interpretations of the concept of laicity presented in this chapter show that the school is permeable to religion. If religion were institutionalized or if it were invited in by the pupils themselves or the different partners in the educational milieu, it cannot be detached from the school. In an attempt to clarify certain idiosyncrasies about the school/religion duality, we have decided here to look at the questions raised by a group of trainee teachers during a course that we organized on this subject. ${ }^{6}$ Even though there were a very large number of questions, we have grouped them into two major categories: religiously inspired festivals within the school; and the religious significance of certain choices of clothing.

We will begin with the matter of religious festivals. Numerous schools celebrate Christmas and Easter, festivals of Christian origin, by involving the pupils in handicrafts, songs and drawings on this theme. The questions by our future teachers focused principally on the desire for justice: can it be correct to do this in a classroom shared by numerous confessions? Are we respecting laicity by decorating a Christmas tree and opening an Advent calendar? Firstly, it seems to us essential to take these questions seriously, since they involve as much the neutrality of the school and the teacher as the pupils' and their parents' freedom of belief. In order to propose a reply, our thoughts are organized into two themes: arguments based on the key concepts of intercultural approaches; and arguments based on questions about the present significance of religious festivals.

As far as concepts are concerned, Geerts (2012) proposes to analyse religious festivals through cultural relativism and cultural imperialism. These two concepts throw light on different dangers concerning how to deal with religious diversity in the school. Firstly, cultural relativism, pushed to extremes, would bring "as an inevitable consequence, either a total deconfessionalization of the calendar or a rapid expansion of public holidays and other festivals with the intention of satisfying everyone without favouring anyone" (Geerts, 2012, p. 28). In contrast, cultural imperialism would mean imposing one dominant religious culture without considering other people's affiliations and without bearing in mind the dynamism of cultures and religions (which would then be considered as immutable) (Geerts, 2012). If neither of these solutions is workable, they do at least highlight the tensions involved when considering religious diversity in places already permanently marked by their history and their cultures, but affected by on-going developments.

\footnotetext{
${ }^{6}$ The students' questions are a source of inspiration; they may have been reworded or modified for the purposes of this chapter.
} 
To allow the trainee teachers to pursue their reflection, we proposed to them to weigh up the value of religious festivals today. For example, the Advent calendar, even though it once represented the expectation of the coming of Christ, is today a cultural and commercial practice very often without any religious significance. For Switzerland, it is a marvellous occasion to sell more chocolate. Moreover, if today an Advent calendar in the classroom has nothing Christian about it (in its design, etc.), this does not throw any doubt on its origin: inspired by this object, the teacher might then propose a critical analysis comparing religious celebrations. Without proselytism, once it has entered the classroom it is possible to tackle religion by making it a subject of knowledge. To speak about Christmas in a town blazing with seasonal decorations is not without sense. It is an opportunity to understand the history of the place where one lives, to understand the behaviour of those surrounding the pupils, to share one's own practices (a child who does not celebrate Christmas could use the occasion of a discussion on this subject to describe other religious celebrations), and to extend critical reflection to the whole world. Concerning this reflection on the present meaning of religious festivals, Geerts (2012) explained that:

It seemed interesting to us to think about the meaning of such and such a festival. Not its traditional meaning but its meaning today, taking place in the daily life of our society, while accepting the idea that every society contains a cultural dimension that it would be useless to want to eradicate but also that culture is an evolving process, in which every expression ought to be evaluated by the extent to which the majority of citizens appreciate it today (Geerts, 2012, p. 31).

Then comes the question of the pupils' choice of clothes. When they convey religious meaning, they may even compromise the teacher's actions: what can one say? What can one do when a pupil arrives at the school wearing a veil or when she only has the right to swim in a burkini? Given that we have mentioned the veil in the on-going discussions dealing with religious questions within the school, it is normal that the trainee teachers' questions focused on this item. Nevertheless, their proposals led us to examine closely clothing choices with religious meanings and those with artistic, political, cultural, etc., meanings.

In order to reply to their questions, let us take the example of a swimming lesson in a burkini: does it enable the child in question's rights to be protected? On one side, the pupil maintains the association with the class, the teaching and the family values; on the other, a different outfit is imposed on her likely to create a barrier between her and the group. Firstly, in reply to this question proposed by a future teacher, we do not have information about the family's attitude available: does this attitude form part of the family's global religious withdrawal placing the child and her development in danger? Or is it situated in a context where the link with the school is sufficiently important for the family to seek a possible compromise? Secondly, we may ask ourselves questions about the preparation of the class group; it is entirely possible that such a costume draws astonishment, curiosity, shock or sometimes even derision. Nevertheless, if an attitude of openness to otherness has been cultivated in the class, the situation will not be the same and will not give rise to the same reaction. 
Obviously, laws and recommendations exist issued by the existing State/national institutions; despite all their good intentions, they still provide the teacher with a fair amount of liberty. In the Canton of Geneva, they are told that the wearing of the veil is possible as long as it is not associated with a proselytizing attitude and does not "interfere with public interest, and the rights of children and others" (DIP, 2016, p. 22). It is up to the teachers to decide what to do about the veil and to adjust their attitude accordingly. It is therefore essential that teachers have the ability to analyse these situations so as not to react too hastily. Three guidelines might assist them in this analysis:

1. The guarantee of the child's rights;

2. The creation of a critical spirit (among the pupils);

3. The primacy of the child's interests.

These three lines of approach allow a situation to be analysed, but it is obvious that one must abandon any idea that a perfect answer exists. This is also one of the issues typical of intercultural approaches in education: they are dynamic, subject to numerous tensions and therefore equally subject to numerous interpretations. It is for these reasons that our intention here is to provide the keys for interpretation which seem to us justified in the name of the approaches defended in this book, but we are not in any way proposing ready-made responses to questions associated with religion within the school.

\section{Conclusion}

In this chapter, we have drawn attention to the difficulties when considering religion within the educational institution. Intercultural approaches in education provide numerous opportunities for reflection on this subject. They particularly allow us to reaffirm the necessity of avoiding any essentialist definition of culture and, in this case, of religion. However, among the numerous components of culture, it is religion, which represents the greatest temptation towards essentialism. Religions appear as millennial, immutable and pure, and sometimes safeguard the monopoly of divine truth. To consider religion as a fixed entity gives an illusion of coherence and may lead to adopting behaviour on the basis of a religious affiliation. Further to this risk, one must consider religion as at once developed, visible, public, but at the same time as something personal, private that may be interpreted in a thousand different ways.

By posing different questions, this chapter shows that taking religion into account within an educational institution is marked by a robust complexity and ambiguity: What is important? How should it be tackled? What limits should be set for dealing with religious diversity? The definition of the key concepts required for an analysis of this theme demonstrates the tensions generated by this complexity—and this already 
from a semantic point of view. Laicity and its numerous interpretations, as well as the many ways it is implemented (illustrated in our analysis of the three national contexts) is a true example.

But then, one could conclude that this chapter has not replied in any way to the expectations of a school searching for answers on the religious question. Indeed, the unique answer that we can (and wish) to express here is the need for constant questioning. Intercultural approaches are on the move, both subject to changes in the world and inspired by them. Therefore, this chapter is designed to stimulate educators' thinking so that they develop a thoughtful practice when taking religion into account in the classroom.

However, as has been mentioned in this chapter, several lines of thought can be pursued. Firstly, one of them is considering the diversity of visions of the world, of life and of spiritualities: "The advantage of this option is, through intercultural approaches, to introduce the pupils to a religious relativism. Religious otherness becomes possible and contributes to struggling against the restriction of religious certainties transmitted by families and original communities" (Akkari, 2016, p. 44).

Secondly, on the basis of the analyses proposed in this chapter, a second line to be explored would be how to include religion in the school. By routinely taking it into account, it may be possible to control it (and not reject it as a prohibition likely to be contravened) and studied in an open and critical way. Its theoretical inclusion in the school would enable a calm discussion to take place manifested by respect and consideration. The need to establish limits (the rights of the child, a critical spirit (particularly concerning male/female equality) and living together) will be strengthened so as to guarantee respect for each person's cultural and religious identity.

Today, if we examine the discussions in the media, it would seem that it is the ostentatious display of religious convictions and the demand for (un)reasonable exceptions that are the most difficult issues. To incorporate religion into the school would require adopting a clear position on these matters: should obvious signs of religious affiliation be considered as a fixed representation of a conviction? Could they be viewed as diverse and personal expressions of faith? Here, once again, the three guidelines mentioned previously could be useful in reaching a judicious decision.

Finally, it should be recalled that, as far as intercultural approaches are concerned, social justice, harmonious living together, interactions and experiences across cultural frontiers are the most important objectives. They should always be borne in mind if we wish to take religion into account in an intercultural perspective. 
Open Access This chapter is licensed under the terms of the Creative Commons Attribution 4.0 International License (http://creativecommons.org/licenses/by/4.0/), which permits use, sharing, adaptation, distribution and reproduction in any medium or format, as long as you give appropriate credit to the original author(s) and the source, provide a link to the Creative Commons license and indicate if changes were made.

The images or other third party material in this chapter are included in the chapter's Creative Commons license, unless indicated otherwise in a credit line to the material. If material is not included in the chapter's Creative Commons license and your intended use is not permitted by statutory regulation or exceeds the permitted use, you will need to obtain permission directly from the copyright holder.

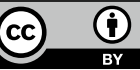

